Editorials

\title{
Chasing the Fat Demon: Fat Chance, Buddy?
}

\author{
${ }^{1}$ David L. Katz, ${ }^{2}$ Joachim Storsberg and ${ }^{3}$ Christian Schmidt \\ ${ }^{I}$ Yale University Prevention Research Center; Griffin Hospital; Derby, CT, USA \\ ${ }^{2}$ Fraunhofer-Institute for Applied Polymer Research (IAP), \\ Division of Life Science and Bioprocesses, Department of Biomaterials and Healthcare, Potsdam-Golm, Germany \\ ${ }^{3}$ Editorial Office, The American Journal of Immunology, S-207, 244, 5th Avenue, New York, NY, 10001 USA and \\ S-71, 1A, 400, King William St, Adelaide, SA 5000, Australia
}

Article history

Received: 22-05-2017

Revised: 25-05-2017

Accepted: 25-05-2017

Corresponding Author:

Christian Schmidt

Editorial Office, The American

Journal of Immunology, S-207,

244, 5th Avenue, New York,

NY, 10001 USA and S-71, 1A,

400, King William St,

Adelaide, SA 5000, Australia

Email: schmidt102@gmail.com

David L. Katz

Yale University Prevention

Research Center; Griffin

Hospital; Derby, CT, USA

Email: david.katz@yale.edu

\begin{abstract}
The question whether aberrant signaling of immune cells are causing obesity, or whether external influences, such as activity patterns, manifestations of stress responses, or hormonal imbalances constitute onsets of a self-enforcing commitment toward metabolic syndrome and obesity is uncertain. Here, we outline choice examples of basic molecular immunology and illuminate them in the context of observations, so far not disputed by public health clinicians, to provide a critical outlook at this pandemic of industrialized nations.
\end{abstract}

Keywords: Molecular Immunology, Obesity, Public Health

\section{Introduction}

Science is an interesting profession. At times, one could get caught up in his or her own world of thoughts, perception, far away from reality, sometimes referred to as the proverbial ivory tower (Lederberg, 1972). Science for the sake of science is, per se, not without merit, with our fragmented understanding of a given issue providing ample justification for experimentation to provide rational basis for a more complete explication, even though one might not avoid the issue of clearly usage of terms within their framework of credible means, such as reasonable interpretation, actual knowledge, data and context, leaving emphasis on the proper context and validation of data as impetus for this editorial for further consideration (Dreyer et al., 2000; Schmidt and Brown, 2015; Storsberg and Schmidt, 2015; Brown et al., 2016).

In the context of data, we wished to illuminate whether metabolic syndrome is caused by aberrations in immune cell signaling, see, for instance Purkayastha and Cai (2013) for further reading on recent progress on exploring the issue surrounding abnormalities in neuro- immunology and metabolic syndrome. For the sake of a convenient argument and not to select out this particular study for any other motive at all than sheer convenience, we, first, wish to direct the reader's attention to a perfectly sound report, where in both, mice and patients, adipose-associated $\mathrm{CD} 11 \mathrm{c}^{+} \mathrm{CD} 1 \mathrm{c}^{+}$dendritic cells are used to correlate their immunobiology with obesityassociated insulin resistance (Bertola et al., 2012). A subsequent study, argued with experimental data beyond a reasonable doubt and equally sound, Zlotnikov-Klionsky et al. (2015) refined the description of underlying subpopulations, termed perforin-positive dendritic cells and found that perforin-positive dendritic cells, from a Lin-Scal ${ }^{+} \mathrm{c} \mathrm{Kit}^{+}$hematopoietic source, transplanted into CD4 or CD8-depleted ItgaxDTA-Prfl ${ }^{-1 /}$ and WT-Prfl ${ }^{-/-}$chimeras yielded phenomena related to metabolic syndrome and obesity in comparison to their respective controls.

Still one cannot avoid facing the lingering issue of whether the populations described by Bertola et al. (2012) are truly comparable with the subpopulation described by Zlotnikov-Klionsky et al. (2015), let alone 
the unresolved issue of the suitability of murine study models of immunity, see Seok et al. (2013; Takao and Miyakawa, 2015) for excellent demonstrations of both viewpoints, the problem of whether using those perforinpositive cells in mice or, if so, in man, as therapeutic or diagnostic tool, can be regarded as cause of metabolic syndrome or a result of a long list of events leading to it. In other words and leaning on a recent review from one of the pioneers in cancer research (Knudson, 2000), are we sure which fat demon to hunt?

Are we even sure that we need to hunt one demon, or is there a whole family of them (Nawaz et al., 2001; Shuval et al., 2017)? One could paraphrase the abovestated problem more nuanced in a series of topics, such as the extent to which obesity, per se, influences immunity- as opposed to a set of factors that influence both immunity and weight (McLaughlin et al., 2017); whether obesity, in turn, is associated with the factors the cause obesity, e.g., dietary, activity and sleep pattern, psychological stress and hormonal balance, to name a few (Girod and Brotman, 2003) and, associations between weight status and the status of the microbiome (Turnbaugh et al., 2006). In a sense, our fragmented understanding of the issue surrounding the extent to which obesity, per se, influences immunity- as opposed to a set of factors that influence both immunity and weight, per definitionem, determines therapeutic approaches because we simply don't know what we don't know (Pawson et al., 2011).

Inflammation, impaired immune system function and perturbations of the microbiome could be both cause and effect of obesity. Dietary patterns conducive to the propagation of chronic disease via inflammation and other pathways of pathogenesis, for example, are generally conducive to obesity as well (Katz and Meller, 2014). So, too, are other aspects of lifestyle (Sagner et al., 2014). Advances in our understanding of mechanistic pathways need not preclude concomitant attention to established causes.

\section{Conclusion}

With our fragmented understanding of the molecular pathways involved in the pathogenesis and progression of metabolic syndrome and, ultimately, obesity, substantial precedent, such as Bhurosy and Jeewon (2014; Herrera et al., 2011) and the above, does not, in and of themselves, mount sufficient rationale to preventing one from considering what is known about the aspect of changing addictive behavior (Prochaska et al., 1992): Such processes are seldom linear and benefit greatly from the creation of positive enforcement loops. All this hinges on the motivation to open the hunting season for the fat demon, even if chances of success may be slim.

\section{Author's Contributions}

Christian Schmidt: Wrote the first draft of the paper.

David L. Katz, Joachim Storsberg: Provided critical input and assisted in revising and improving the paper.

\section{Ethics}

David L. Katz, Joachim Storsberg, Christian Schmidt: Report and certify no conflicts of interest with regard to this paper, including, but not limited to participation in speakers' bureaus, honoraria, employment, equity interest, nor non-financial interest in the topics or evidence presented in this paper.

Christian Schmidt: Is a member of the Editorial Board of The American Journal of Immunology, is waived from the Article Processing fee for this contribution and receives no remuneration for the editorial work.

\section{References}

Bertola, A., T. Ciucci, D. Rousseau, V. Bourlier and C. Duffaut et al., 2012. Identification of adipose tissue dendritic cells correlated with obesityassociated insulin-resistance and inducing Th17 responses in mice and patients. Diabetes, 61: 2238-2247. DOI: $10.2337 / \mathrm{db} 11-1274$

Bhurosy, T. and R. Jeewon, 2014. Overweight and obesity epidemic in developing countries: A problem with diet, physical activity, or socioeconomic status? Scientific World J., 2014: 964236-964236. DOI: 10.1155/2014/964236

Brown, M.A., J. Storsberg and C. Schmidt, 2016. Where the future is being made today. Am. J. Immunol., 12: 17-19. DOI: 10.3844/ajisp.2016.17.19

Dreyer, W., W.H. Müller and W. Weiss, 2000. Tales of thermodynamics and obscure applications of the second law. Continuum Mechan. Thermodynam., 12: 151-184. DOI: 10.1007/s001610050133

Girod, J.P. and D.J. Brotman, 2003. The metabolic syndrome as a vicious cycle: Does obesity beget obesity? Med. Hypotheses, 60: 584-589. DOI: 10.1016/S0306-9877(03)00053-7

Herrera, B.M., S. Keildson and C.M. Lindgren, 2011. Genetics and epigenetics of obesity. Maturitas, 69: 41-49. DOI: 10.1016/j.maturitas.2011.02.018

Katz, D.L. and S. Meller, 2014. Can we say what diet is best for health? Ann. Rev. Public Health, 35: 83-103. DOI: 10.1146/annurev-publhealth-032013-182351

Knudson, A.G., 2000. Chasing the cancer demon. Ann. Rev. Genet., 34: 1-19.

DOI: 10.1146/annurev.genet.34.1.1

Lederberg, J., 1972. The freedoms and the control of science: Notes from the ivory tower. S. Cal. L. Rev., 45: 596-614. 
McLaughlin, T., S.E. Ackerman, L. Shen and E. Engleman, 2017. Role of innate and adaptive immunity in obesity-associated metabolic disease. J. Clin. Invest., 127: 5-13. DOI: 10.1172/JCI88876

Nawaz, H., W. Chan, M. Abdulrahman, D. Larson and D.L. Katz, 2001. Self-reported weight and height: Implications for obesity research. Am. J. Preventive Med., 20: 294-298. DOI: $10.1016 / \mathrm{S} 0749-3797(01) 00293-8$

Pawson, R., G. Wong and L. Owen, 2011. Known knowns, known unknowns, unknown unknowns: The predicament of evidence-based policy. Am. J. Evaluat., 32: 518-546. DOI: $10.1177 / 1098214011403831$

Prochaska, J.O., C.C. DiClemente and J.C. Norcross, 1992. In search of how people change: Applications to addictive behaviors. Am. Psychol., 47: 1102-1114. DOI: 10.1037/0003-066X.47.9.1102

Purkayastha, S. and D. Cai, 2013. Neuroinflammatory basis of metabolic syndrome. MolMetab, 2: 356-363. DOI: 10.1016/j.molmet.2013.09.005

Sagner, M., D. Katz, G. Egger, L. Lianov and K.H. Schulz et al., 2014. Lifestyle medicine potential for reversing a world of chronic disease epidemics: From cell to community. Int. J. Clin. Pract., 68: 1289-1292. DOI: 10.1111/ijcp.12509

Schmidt, C. and M.A. Brown, 2015. Relating the pendulum of democracy with oncology research. J. Clin. Exp. Oncol., 4: 3-3. DOI: $10.4172 / 2324-9110.1000 \mathrm{e} 109$
Seok, J., H.S. Warren, A.G. Cuenca, M.N. Mindrinos and H.V. Baker et al., 2013. Genomic responses in mouse models poorly mimic human inflammatory diseases. Proc. Natl. Acad. Sci. USA, 110: 3507-3512. DOI: $10.1073 /$ pnas. 1222878110

Shuval, K., T. Leonard, J. Drope, D.L. Katz and A.V. Patel et al., 2017. Physical activity counseling in primary care: Insights from public health and behavioral economics. CA Cancer J. Clin., 67: 233-244. DOI: 10.3322/caac. 21394

Storsberg, J. and C. Schmidt, 2015. Nanomaterials-tools, technology and methodology of nanotechnology based biomedical systems for diagnostics and therapy. Biomedicines, 3: 203-223.

DOI: $10.3390 /$ biomedicines3030203

Takao, K. and T. Miyakawa, 2015. Genomic responses in mouse models greatly mimic human inflammatory diseases. Proc. Natl. Acad. Sci. USA, 112: 1167-1172. DOI: 10.1073/pnas.1401965111

Turnbaugh, P.J., R.E. Ley, M.A. Mahowald, V. Magrini and E.R. Mardis et al., 2006. An obesity-associated gut microbiome with increased capacity for energy harvest. Nature, 444: 1027-1131. DOI: 10.1038 /nature 05414

Zlotnikov-Klionsky, Y., B. Nathansohn-Levi, E. Shezen, C. Rosen and S. Kagan et al., 2015. Perforinpositive dendritic cells exhibit an immunoregulatory role in metabolic syndrome and autoimmunity. Immunity, 43: 776-787.

DOI: 10.1016/j.immuni.2015.08.015 